\title{
Relationship between CYP17A1 genetic polymorphism and coronary artery disease in a Chinese Han population
}

Chuan-Fang Dai, Xiang Xie*, Yi-Ning Yang, Xiao-Mei Li, Ying-Ying Zheng, Zhen-Yan Fu, Fen Liu, Bang-Dang Chen, Min-Tao Gai and Yi-Tong Ma*

\begin{abstract}
Background: CYP17A1 gene encodes P450c17 proteins, which is a key enzyme that catalyzes the formation of sex hormones. Many clinical studies showed that sex hormones levels play an important role in the pathogenesis of coronary artery disease (CAD). However, the relationship between CYP17A1 genetic polymorphisms and CAD remains unclear. The aim of this study was to investigate the association of CYP17A1 genetic polymorphisms with CAD in a Han population of China.

Methods: A total of 997 people include 490 patients and 507 controls were selected for the present study. Five single-nucleotide polymorphisms (SNPs) (rs4919686, rs1004467, rs4919687, rs10786712, and rs2486758) were genotyped by using the real-time PCR (TaqMan) method.

Results: For men, the rs 10786712 was found to be associated with CAD in a recessive model $(P=0.016)$, after adjustment of the major confounding factors, the significant difference was retained (OR $=1.644,95 \%$ confidence interval $[\mathrm{Cl}]: 1.087-2.488, \mathrm{P}=0.019$ ). For women, the rs1004467 was also found to be associated with $C A D$ in a dominant model $(P=0.038)$, the difference remained statistically significant after multivariate adjustment $(O R=1.623,95 \%$ Cl: 1.023-2.576, $P=0.040$ ). The distribution of rs4919687 genotypes showed a significant difference between CAD and control participants in a recessive model $(P=0.019)$, the significant difference was retained after adjustment for covariates $(\mathrm{OR}=0.417,95 \% \mathrm{Cl}: 0.188-0.926, \mathrm{P}=0.032)$.

Conclusion: Rs1004467, rs4919687, rs10786712 of CYP17A1 gene are associated with CAD in Han population of China. The $\Pi$ genotype of rs 10786712 could be a protective genetic marker of CAD in men. The CC genotype of rs1004467 and the AA genotype of rs4919687 could be risk genetic markers of CAD in women. However, large sample size study including other SNPs of CYP17A1 should be performed in future studies.
\end{abstract}

Keywords: CYP17A1, Single nucleotide polymorphism, Coronary artery disease, Case control study

\section{Introduction}

Coronary artery disease (CAD) is a complex multifactorial disorder resulting from several susceptibility genes and multiple environmental determinants [1,2]. Recently, genetic basis of CAD has gained considerable interest [3], heritable factors accounted for $40 \%-60 \%$ in occurrence and development of CAD [4]. Various genes have been shown to be associated with CAD [5,6]. Some large-scale association studies have identified many common, uncommon

\footnotetext{
* Correspondence: xiangxie999@sina.com; myt xj@sina.com Department of Cardiology, First Affiliated Hospital of Xinjiang Medical University, Urumqi 830054, P.R. China
}

\section{(O) BioMed Central}

and functional variants for CAD $[7,8]$. The CYP17A1 gene, located on chromosome 10q24.3, is mainly expressed in the adrenal glands and gonads. This gene encodes a member of enzymes of the cytochrome P450 superfamily. The cytochrome $\mathrm{P} 450$ proteins are monooxygenases and responsible for not only the metabolism of xenobiotics but also a host of endogenous substance whose metabolites have critical roles in the maintenance of cardiovascular health $[9,10]$. Mounting evidences have demonstrated that CYP enzymes are involved in the pathogenesis of CAD. For example, the CYP8A1 predominantly in vascular endothelial and smooth muscle cells, and acts mainly as an enzyme that converts 
prostaglandin $\mathrm{H} 2$ (PGH2) into prostacyclin (PGI2), some studies suggested that gene polymorphisms of CYP8A1 were associated with cardiovascular risk [11]. In addition, CYP1A1, CYP1A2 (metabolize tobacco polycyclic aromatic hydrocarbons and aromatic amines during smoking) $[12,13]$, CYP2C8, CYP2J2 ([EET] synthesis) [14,15], CYP11B2 (aldosterone synthesis) [16], CYP17, and CYP19 (synthesis of sex hormones) [17], have been demonstrated to be associated with CAD.

In humans, CYP17A1 gene is responsible for the synthesis of P450c17 proteins, which is a key enzyme in the steroidogenic pathway. CYP17A1 genetic mutations affect the synthesis of steroids, which are the precursors of sex hormones. Some evidences have indicated that the levels of sex hormones can affect the development of cardiovascular and cerebrovascular diseases [18].

Recently, two large-scale association analyses identified 13 new susceptibility loci for CAD including CYP17A1 gene [19,20]. Adam S Butterworth et al. [21] selected 15596 patients with CAD and 34992 controls to examine 2100 genes including 49094 genetic variations, and suggested that CYP17A1 gene is one of the susceptibility genes for CAD. However, the relation between CYP17A1 gene and $\mathrm{CAD}$ in Chinese population remains unclear. Therefore, in the present study, we aimed to assess the association between the polymorphisms of CYP17A1 and CAD in Chinese Han population.

\section{Methods}

\section{Ethical approval of the study protocol}

This study was conducted according to the standards of the Declaration of Helsinki, and was approved by the Ethics Committee of the First Affiliated Hospital of Xinjiang Medical University (Xinjiang, China). Written informed consent was obtained from each participant, and explicitly provided permission for DNA analyses as well as collection of relevant clinical data.

\section{Subjects}

Study population was from a Han population who lived in the Xinjiang Uygur Autonomous Region of China, all subjects attended as inpatients and had a differential diagnosis for chest pain encountered in the Cardiac Catheterization Laboratory of First Affiliated Hospital of Xinjiang Medical University from 2007 to 2013. Approximately 3000 patients undergo coronary angiography every year and we selected almost 1000 Han CAD patients and 1000 healthy persons diagnosed by angiography from 2007 to 2013. Highly skilled physicians were undertaken the coronary angiography using the Judkins approach. Least two experienced imaging specialists were interpreted the findings of coronary angiography, finally, the diagnosis of CAD was made according to the angiography report. All CAD groups defined as the presence of at least one significant coronary artery stenosis of $>50 \%$ luminal diameter. Patients with congenital heart disease, multiple organ failure syndrome, malignancy or chronic inflammatory disease were excluded. According to the exclusion criteria, 124 people were excluded from the 1000 CAD patients. Each control subject also underwent a coronary angiogram and did not show coronary artery stenosis. These individuals had no electrocardiographic signs of CAD, regional wall motion abnormalities, and no relevant valvular abnormalities in echocardiograms. Control subjects with CAD and any neoplasm, cardiomyopathy or severe illness limiting life expectance or refusing consent were excluded, according to the exclusion criteria, 82 people were excluded from the 1000 healthy persons. Finally, to ensure matching for age and gender, we selected 490 patients and 507 healthy persons from the 876 CAD patients and 918 healthy persons. Some of the controls have hypertension, and diabetes mellitus, which means control group expose to the same risk factors of CAD while the results of coronary angiogram are normal. The diagnosis of hypertension was established if patients were on antihypertensive medication or if the mean of 3 measurements of systolic blood pressure (SBP) at least $140 \mathrm{mmHg}$, and/or diastolic blood pressure (DBP) at least $90 \mathrm{mmHg}$, or a previous diagnosis of hypertension and the use of antihypertensive medication; Diabetes mellitus was defined on the basis of the American Diabetes Association [22]. In addition, individuals with fasting plasma glucose $>7.0 \mathrm{mmol} / \mathrm{L}$ or with a history of diabetes or treatment with hypoglycemic agent were considered diabetic. Smoking was classified as smokers (including current or ex-smokers) or non-smokers.

\section{Blood collection and DNA extraction}

Before cardiac catheterization, $5 \mathrm{ml}$ of fasting venous blood drawn by venipuncture in the Cardiac Catheterization Laboratory were taken from all participants. The blood samples were collected into tubes containing ethylene diamine tetraacetic acid (EDTA), and centrifuged at $4000 \times \mathrm{g}$ for $5 \mathrm{~min}$ to separate the plasma content (including plasma, serum and blood cells). Genomic DNA was extracted from the peripheral leukocytes using standard phenolchloroform method [23]. The DNA samples were stored at $-80^{\circ} \mathrm{C}$ for future analysis. Before genetic analysis, the final concentration of the DNA was diluted to $50 \mathrm{ng} / \mu \mathrm{L}$.

\section{Genotyping}

There are 662 SNPs for the human CYP17A1 gene listed in the National Center for Biotechnology Information SNP database (http://www.ncbi.nlm.nih.gov/SNP). Using Haploview 4.2 software and International HapMap Project website phase I \&II database (http://www.hapmap.org), we obtained five tag SNPs (SNP1: rs4919686, SNP2: rs1004467, SNP3: rs4919687, SNP4: rs10786712, SNP5: rs2486758) by using minor allele frequency (MAF) $\geq 0.05$ and linkage disequilibrium patterns with $r^{2} \geq 0.8$ as a cut 
off. Genotyping in the present case-control study was confirmed by the TaqMan SNP Genotyping Assay (Applied Biosystems, Foster City, CA, USA). The primers and probes used in the TaqMan SNP Genotyping Assays were chosen based on information available at the ABI Web site (http://myscience.appliedbiosystems.com). Thermal cycling was done using the Applied Biosystems 7900HT Fast Real-Time PCR System. Plates were read on the sequence detection systems (SDS) automation controller software v2.3 (ABI). PCR amplification was performed using $2.5 \mu \mathrm{L}$ of TaqMan Universal Master Mix, $0.15 \mu \mathrm{L}$ probes and $1.85 \mathrm{ddH}_{2} \mathrm{O}$ in a $6-\mu \mathrm{L}$ final reaction volume containing $1 \mu \mathrm{L}$ DNA. The thermal cycling conditions were as follows: $50^{\circ} \mathrm{C}$ for $2 \mathrm{~min} ; 95^{\circ} \mathrm{C}$ for $10 \mathrm{~min} ; 50$ cycles of $95^{\circ} \mathrm{C}$ for $15 \mathrm{~s}$; and $60^{\circ} \mathrm{C}$ for $1 \mathrm{~min}$. Thermal cycling was performed using the Sequence Detection Systems (SDS) automation controller software v2.3 (ABI).

\section{Biochemical analysis}

Serum concentrations of glucose (Glu), total cholesterol (TC), triglyceride (TG), high-density lipoprotein cholesterol (HDL-C), low-density lipoprotein cholesterol (LDL-C), blood urea nitrogen (BUN), creatinine $(\mathrm{Cr})$ and uric acid (UA) were measured using standard methods in the Central Laboratory of First Affiliated Hospital of Xinjiang Medical University as described previously [24-26].

\section{Statistical analysis}

Data analysis was carried out using the computer software Statistical Package for Social Sciences SPSS 17.0 for Windows (SPSS Institute, Chicago, USA). Hardy-Weinberg equilibrium was assessed by $\chi^{2}$ analysis. Differences in measurement variables (e.g. age, BMI, TC, TG, HDL-C, LDL-C) were analyzed using means \pm standard deviation (SD). The difference between the CAD and control groups was analyzed using an independent-sample t-test. Differences in frequencies of smoking, drinking, hypertension, diabetes mellitus, and CYP17A1 genotypes were analyzed using $X^{2}$ test or Fisher's exact test while appropriate. $P$-value $<0.05$ was considered statistically significant. Logistic regression analyses with effect ratios (odds ratio [OR] and 95\% CI) were used to assess contribution of major risk factors. Statistical significance was established at $\mathrm{P}<0.05$. Based on the genotype data of the genetic variations, we performed linkage disequilibrium (LD) analysis and haplotype-based case-control analysis, using the expectation maximization (EM) algorithm [27] and the software SHEsis (http://analysis.bio-x.cn/SHEsisMain. $\mathrm{htm})$. The pairwise linkage disequilibrium analysis was performed using five SNP pairs. We used $\left|D^{\prime}\right|$ values of $>0.5$ to assign SNP locations to one haplotype block. Single nucleotide polymorphisms with an $r^{2}$ value of $<0.5$ were selected as tagged. In the haplotype-based case-control analysis, haplotypes with a frequency of $<0.03$ were excluded. The frequency distribution of the haplotypes was calculated by performing a permutation test using the bootstrap method.

\section{Results}

Table 1 shows demographic and clinical characteristics of the study participants. There was no significant difference in age between CAD patients and control subjects. It means the study was an age-matched case-control study. For total subjects, men, and women participants, there was no significant difference in the following variables between the CAD patients and the control participants: hypertension, smoking, drinking, diastolic blood pressure (DBP), and serum concentration of total cholesterol, low-density lipoprotein cholesterol, and uric acid. The incidence of diabetes, and the plasma concentration of glucose, creatinine was significantly higher in subjects with CAD than in the controls. For total participants, the following values were significantly higher for the CAD patients as compared to the control subjects: systolic blood pressure (SBP), the plasma concentration of triglyceride, high-density lipoprotein cholesterol. And the plasma concentration of HDL was significantly lower for patients with CAD than for control participants. For women, the systolic blood pressure (SBP), triglyceride, were significantly higher for patients with CAD than for control participants.

Table 2 shows the distribution of genotypes and alleles of SNP1, SNP2, SNP3, SNP4 and SNP5 for the CYP17A1 gene. The genotype distributions for each SNP were in good agreement with the predicted Hardy-Weinberg equilibrium values (data not shown). For total, men, and women subjects, the distribution of SNP1 (rs4919686) and SNP5 (rs2486758) genotypes, dominant model, recessive model, and additive model did not show a significant difference between CAD and control participants $(P>0.05$, respectively). For total participants, the other three SNPs (SNP2: rs1004467, SNP3: rs4919687, SNP4: rs10786712) genotypes, dominant model, recessive model, additive model, and allele frequency also did not show a significant difference between the CAD patients and the control subjects $(\mathrm{P}>0.05$ respectively). For men subjects, distribution of rs10786712 recessive model $(C C+C T$ vs. TT) showed difference between CAD and control subjects $(P=0.016)$, and the recessive model was significantly lower in subjects with CAD than in controls $(75.7 \%$ vs. $66.1 \%)$. For women participants, the dominant model $(\mathrm{CC}+\mathrm{CT}$ vs. TT) of rs1004467 showed difference between $\mathrm{CAD}$ and control subjects $(\mathrm{P}=0.038)$, and the dominant model was significantly higher in CAD patients than in control participants $(76.6 \%$ vs. $67.8 \%)$. The distribution of the recessive model (AG + GG vs. AA) of rs4919687 was significantly higher in patients with CAD than in control participants $(89.8 \%$ vs. $95.5 \%)$, and showed a significant difference between $C A D$ and control subjects $(P=0.019)$. 
Table 1 Demographic and clinical characteristics of study participants

\begin{tabular}{|c|c|c|c|c|c|c|c|c|c|}
\hline & \multicolumn{3}{|l|}{ Total } & \multicolumn{3}{|l|}{ Men } & \multicolumn{3}{|l|}{ Women } \\
\hline & CAD & Control & $P$ value & CAD & Control & $P$ value & CAD & Control & $P$ value \\
\hline Number(n) & 490 & 507 & & 278 & 263 & & 212 & 244 & \\
\hline Age, mean (SD) & $61.94(9.97)$ & $61.20(10.07)$ & 0.242 & $60.65(11.11)$ & $59.70(11.32)$ & 0.326 & $63.63(7.95)$ & $62.81(8.23)$ & 0.280 \\
\hline $\mathrm{EH}, \mathrm{n}(\%)$ & $236(48.2)$ & $219(43.2)$ & 0.115 & $119(42.8)$ & $106(40.3)$ & 0.555 & $117(55.2)$ & $113(46.3)$ & 0.059 \\
\hline Diabetes, n (\%) & $102(20.8)$ & $40(7.9)$ & $<0.001$ & 55 (19.8) & $23(8.7)$ & $<0.001$ & $47(22.2)$ & $17(7.0)$ & $<0.001$ \\
\hline Smoking, n (\%) & $63(12.9)$ & $50(9.9)$ & 0.136 & 60 (21.6) & 49 (18.6) & 0.392 & $3(1.4)$ & $1(4)$ & 0.519 \\
\hline Drinking, n (\%) & $55(11.2)$ & $43(8.5)$ & 0.146 & $54(19.4)$ & $43(16.3)$ & 0.371 & $1(5)$ & 0 & 0.994 \\
\hline BMI, mean (SD) & $25.85(3.41)$ & $25.48(3.26)$ & 0.076 & 26.41 (3.35) & $25.72(3.37)$ & 0.018 & 25.26 (3.39) & $25.16(3.10)$ & 0.753 \\
\hline SBP, mean (SD) & $138.74(26.35)$ & 135.49 (24.09) & 0.045 & $136.44(25.77)$ & $134.82(23.11)$ & 0.448 & $141.84(26.87)$ & $136.20(25.13)$ & 0.024 \\
\hline DBP, mean (SD) & $85.78(18.10)$ & $84.18(15.66)$ & 0.143 & $85.48(18.42)$ & $84.52(15.94)$ & 0.521 & $86.17(17.71)$ & $83.81(15.38)$ & 0.136 \\
\hline Glu, mean (SD) & $6.28(2.69)$ & 5.55 (1.73) & $<0.001$ & $6.21(2.77)$ & $5.62(1.92)$ & 0.004 & $6.37(2.57)$ & $5.48(1.50)$ & $<0.001$ \\
\hline TG, mean (SD) & $2.24(2.13)$ & $1.90(1.48)$ & 0.005 & $2.30(2.10)$ & $2.04(1.57)$ & 0.110 & $2.15(2.17)$ & 1.75 (1.37) & 0.026 \\
\hline $\mathrm{TC}$, mean (SD) & $4.25(1.16)$ & $4.33(1.02)$ & 0.306 & $4.06(0.99)$ & $4.18(1.04)$ & 0.160 & $4.51(1.30)$ & $4.48(0.97)$ & 0.777 \\
\hline HDL, mean (SD) & $1.08(0.33)$ & $1.13(0.32)$ & 0.013 & $1.01(0.28)$ & $1.05(0.29)$ & 0.148 & $1.16(0.38)$ & $1.22(0.33)$ & 0.104 \\
\hline LDL, mean (SD) & $2.51(0.94)$ & $2.55(0.86)$ & 0.457 & $2.43(0.91)$ & $2.52(0.89)$ & 0.220 & $2.80(2.46)$ & $2.57(0.82)$ & 0.212 \\
\hline UA, mean (SD) & 320.94 (94.17) & 321.07 (82.94) & 0.982 & 344.51 (91.79) & 348.25 (75.07) & 0.609 & 289.55 (88.13) & $291.72(81.14)$ & 0.788 \\
\hline $\mathrm{Cr}$, mean (SD) & 77.79 (33.00) & 72.21 (17.82) & 0.001 & 84.09 (33.96) & 79.15 (16.84) & 0.033 & 69.39 (29.73) & $64.71(15.71)$ & 0.045 \\
\hline BUN, mean (SD) & $5.38(1.96)$ & $5.29(1.86)$ & 0.446 & $5.54(1.68)$ & $5.51(1.68)$ & 0.822 & $5.17(2.27)$ & $5.05(2.01)$ & 0.562 \\
\hline
\end{tabular}

Data are presented as mean \pm SD or $n(\%)$. Continuous variables are expressed as mean $\pm \mathrm{SD}$. Categorical variables are expressed as percentages. MI, body mass index; BUN, blood urea nitrogen; Cr, creatinine; DBP, diastolic blood pressure; DM, diabetes mellitus; Glu, glucose; TG, triglyceride; TC, total cholesterol; HDL, high density lipoprotein; LDL, low density lipoprotein; EH, essential hypertension; SBP, systolic blood pressure; UA, uric acid.

The $\mathrm{P}$ value of the continuous variables was calculated by the Independent $\mathrm{t}$-test. The $\mathrm{P}$ value of the categorical variables was calculated by Fisher's exact test.

Tables 3, 4, and 5 showed the multivariable logistic regression analyses done with the following variables: prevalence of conventional risk factors for CAD including hypertension, diabetes, smoking and drinking, and plasma concentration of blood glucose, TG, Cr, and SBP. For women (Table 3), after multivariate adjustment, rs1004467 remains significantly association with CAD in dominant model $(\mathrm{OR}=1.623,95 \% \mathrm{CI}$ : $1.023-2.576, \mathrm{P}=$ 0.040); rs4919687 (Table 4) remains significantly association with $\mathrm{CAD}(\mathrm{OR}=0.417,95 \% \mathrm{CI}$ : 0.188-0.926, $\mathrm{P}=$ 0.032 ) in recessive model. For men (Table 5), the significant difference of rs10786712 (OR $=1.644$, 95\% confidence interval $[\mathrm{CI}]: 1.087-2.488, \mathrm{P}=0.019)$ was retained after adjustment of the major confounding factors for CAD in recessive model.

Table 6 shows patterns of linkage disequilibrium (LD) analysis in the CYP17A1. All 5 SNPs are located in one haplotype block for $\left|\mathrm{D}^{\prime}\right|$ values were beyond 0.5 , and all of the $r^{2}$ values were below 0.5. Because the $\left|D^{\prime}\right|$ for SNP2-SNP3 was $<0.5$, this meant that SNP2 and SNP3 could not be used to simultaneously construct haplotypes. As the minor allele frequency of SNP3 was larger than that of SNP2, we constructed haplotypes using SNP1, SNP3, SNP4, and SNP5.

Table 7 shows the result of haplotype analysis. In the haplotype-based case-control analysis, haplotypes were established through different combinations of the 4
SNPs. For total, including men and women, the overall distribution of haplotypes were no significantly different between the CAD patients and the control subjects. For men, the frequencies of the $\mathrm{C}-\mathrm{T}, \mathrm{G}-\mathrm{C}-\mathrm{T}, \mathrm{A}-\mathrm{C}-\mathrm{T}$, and $\mathrm{A}-\mathrm{G}-$ $\mathrm{C}-\mathrm{T}$ haplotypes respectively established by SNP4-SNP5, SNP3-SNP4-SNP5, SNP1-SNP4-SNP5, and SNP1SNP3-SNP4-SNP5 were significantly higher for the CAD patients as compared to the control subjects $(\mathrm{P}=0.047, \mathrm{P}=$ $0.048, \mathrm{P}=0.040$, and $\mathrm{P}=0.039$, respectively). The frequencies of the A-A-T, A-T-T, and A-A-T-T haplotypes respectively established by SNP1-SNP3-SNP5, SNP1SNP4-SNP5, and SNP1-SNP3-SNP4-SNP5 were lower for CAD patients than for control participants $(\mathrm{P}=0.040$, $\mathrm{P}=0.031, \mathrm{P}=0.033$, respectively). For women, the frequency of the A-T, A-A-T, A-A-T, and A-A-T-T haplotypes established by SNP3-SNP4, SNP1-SNP3-SNP4, SNP1-SNP3-SNP5, and SNP1-SNP3-SNP4-SNP5 respectively were significantly higher for the CAD patients as compared to the control subjects $(\mathrm{P}=0.041, \mathrm{P}=0.034$, $\mathrm{P}=0.035$, and $\mathrm{P}=0.045$, respectively).

\section{Discussion}

Relationship between CYP genetic polymorphism and cardiovascular disease (CVD) has been established [10]. In our study, we found the variations in CYP17A1 gene was associated with CAD in a Han population of China, even after multivariate adjustment, the association still 
Table 2 Genotype and Allele distributions in patients with CAD and control participants

\begin{tabular}{|c|c|c|c|c|c|c|c|c|c|c|}
\hline \multirow[t]{2}{*}{ Variants } & & \multicolumn{3}{|l|}{ Total } & \multicolumn{3}{|l|}{ Man } & \multicolumn{3}{|l|}{ Woman } \\
\hline & & CAD, n (\%) & Control, n (\%) & $P$ value & CAD n (\%) & Control n (\%) & $P$ value & CAD n (\%) & Control n (\%) & $P$ value \\
\hline \multicolumn{11}{|l|}{ Rs4919686 (SNP1) } \\
\hline \multirow[t]{3}{*}{ Genotyping } & $\mathrm{AA}$ & $365(76.2)$ & $356(77.1)$ & 0.710 & 205 (75.6) & $181(76.1)$ & 0.836 & $160(76.9)$ & $175(78.1)$ & 0.811 \\
\hline & $A C$ & $110(23.0)$ & $100(21.6)$ & & $63(23.2)$ & $53(22.3)$ & & 47 (22.6) & $47(21.0)$ & \\
\hline & CC & $4(0.8)$ & $6(1.3)$ & & $3(1.1)$ & $4(1.7)$ & & $1(0.5)$ & $2(0.9)$ & \\
\hline \multirow[t]{2}{*}{ Recessive model } & $\mathrm{CC}$ & $4(0.8)$ & $6(1.3)$ & 0.707 & $3(1.1)$ & $4(1.7)$ & 0.863 & $1(0.5)$ & $2(0.9)$ & 1 \\
\hline & $A A+A C$ & $475(99.2)$ & $456(98.7)$ & & $268(98.9)$ & $234(98.3)$ & & 207 (99.5) & $222(99.1)$ & \\
\hline \multirow[t]{2}{*}{ Dominant model } & AA & 365 (76.2) & $356(77.1)$ & 0.756 & 205 (75.6) & $181(76.1)$ & 0.915 & $160(76.9)$ & $175(78.1)$ & 0.765 \\
\hline & $A C+C C$ & 114 (23.8) & 106 (22.9) & & $66(24.4)$ & 57 (23.9) & & $48(23.1)$ & 49 (21.9) & \\
\hline \multirow[t]{2}{*}{ Additive model } & $A C$ & $110(23.0)$ & $100(21.6)$ & 0.627 & $63(23.2)$ & $53(22.3)$ & 0.793 & 47 (22.6) & $47(21.0)$ & 0.685 \\
\hline & $A A+C C$ & $369(77.0)$ & $362(78.4)$ & & $208(76.8)$ & $185(77.7)$ & & $161(77.4)$ & $177(79.0)$ & \\
\hline \multirow[t]{2}{*}{ Allele } & A & $840(87.7)$ & 812 (87.9) & 0.897 & $473(87.3)$ & 415 (87.2) & 0.968 & 367 (88.2) & 397 (88.6) & 0.856 \\
\hline & C & 118 (12.3) & $112(12.1)$ & & $69(12.7)$ & $61(12.8)$ & & 49 (11.8) & $51(11.4)$ & \\
\hline \multicolumn{11}{|l|}{ Rs1004467 (SNP2) } \\
\hline \multirow[t]{3}{*}{ Genotyping } & CC & $86(17.8)$ & 89 (17.5) & 0.993 & $41(14.7)$ & $45(17.1)$ & 0.240 & $45(22.0)$ & $44(18.0)$ & 0.106 \\
\hline & $\mathrm{CT}$ & $250(51.8)$ & $264(52.0)$ & & $138(49.6)$ & $142(54.0)$ & & $112(54.6)$ & $122(49.8)$ & \\
\hline & $\pi$ & $147(30.4)$ & 155 (30.5) & & 99 (35.6) & 76 (28.9) & & $48(23.4)$ & 79 (32.2) & \\
\hline \multirow[t]{2}{*}{ Recessive model } & $\mathrm{CC}$ & $86(17.8)$ & 89 (17.5) & 0.906 & $41(14.7)$ & 45 (17.1) & 0.453 & $45(22.0)$ & $44(18.0)$ & 0.290 \\
\hline & $C T+T$ & 397 (82.2) & 419 (82.5) & & $237(85.3)$ & 218 (82.9) & & 160 (78.0) & $201(82.0)$ & \\
\hline \multirow[t]{2}{*}{ Dominant model } & $\pi$ & $147(30.4)$ & $155(30.5)$ & 0.979 & 99 (35.6) & $76(28.9)$ & 0.095 & $48(23.4)$ & 79 (32.2) & 0.038 \\
\hline & $\mathrm{CC}+\mathrm{CT}$ & $336(69.6)$ & $353(69.5)$ & & $179(64.4)$ & $187(71.1)$ & & 157 (76.6) & $166(67.8)$ & \\
\hline \multirow[t]{2}{*}{ Additive model } & $C T$ & $250(51.8)$ & $264(52.0)$ & 0.948 & $138(49.6)$ & $142(54.0)$ & 0.311 & $112(54.6)$ & $122(49.8)$ & 0.306 \\
\hline & $C C+\pi$ & $233(48.2)$ & $244(48.0)$ & & $140(50.4)$ & $121(46.0)$ & & $93(45.4)$ & $123(50.2)$ & \\
\hline \multirow[t]{2}{*}{ Allele } & C & $422(43.7)$ & $442(43.5)$ & 0.935 & 220 (39.6) & $232(44.1)$ & 0.130 & $202(49.3)$ & $210(42.9)$ & 0.055 \\
\hline & $\mathrm{T}$ & $544(56.3)$ & $574(56.5)$ & & $336(60.4)$ & $294(55.9)$ & & $208(50.7)$ & $280(57.1)$ & \\
\hline \multicolumn{11}{|l|}{ Rs4919687 (SNP3) } \\
\hline \multirow[t]{3}{*}{ Genotyping } & AA & $30(6.3)$ & $24(4.7)$ & 0.551 & $9(3.3)$ & $13(5.0)$ & 0.538 & $21(10.2)$ & $11(4.5)$ & 0.063 \\
\hline & $A G$ & $155(32.4)$ & $171(33.8)$ & & 93 (33.9) & $93(35.5)$ & & $62(30.2)$ & 78 (32.0) & \\
\hline & GG & $294(61.4)$ & $311(61.5)$ & & $172(62.8)$ & $156(59.5)$ & & $122(59.5)$ & $155(63.5)$ & \\
\hline \multirow[t]{2}{*}{ Recessive model } & AA & $30(6.3)$ & $24(4.7)$ & 0.295 & $9(3.3)$ & $13(5.0)$ & 0.328 & $21(10.2)$ & $11(4.5)$ & 0.019 \\
\hline & $A G+G G$ & 449 (93.7) & $482(95.3)$ & & $265(96.7)$ & $249(95.0)$ & & 184 (89.8) & $233(95.5)$ & \\
\hline \multirow[t]{2}{*}{ Dominant model } & GG & $294(61.4)$ & $311(61.5)$ & 0.978 & $172(62.8)$ & $156(59.5)$ & 0.443 & $122(59.5)$ & $155(63.5)$ & 0.384 \\
\hline & $A A+A G$ & 185(38.6) & $195(38.5)$ & & $102(37.2)$ & $106(40.5)$ & & $83(40.5)$ & $89(36.5)$ & \\
\hline \multirow[t]{2}{*}{ Additive model } & AG & $155(32.4)$ & $171(33.8)$ & 0.632 & 93 (33.9) & $93(35.5)$ & 0.705 & $62(30.2)$ & 78 (32.0) & 0.695 \\
\hline & $\mathrm{AA}+\mathrm{GG}$ & $324(67.6)$ & $335(66.2)$ & & $181(66.1)$ & $169(64.5)$ & & $143(69.8)$ & $166(68.0)$ & \\
\hline Allele & A & $215(22.4)$ & 219 (21.6) & 0.668 & $111(20.3)$ & 119 (22.7) & 0.328 & $104(25.4)$ & $100(20.5)$ & 0.083 \\
\hline & G & 743 (77.6) & 793 (78.4) & & $437(79.7)$ & 405 (77.3) & & $306(74.6)$ & $388(79.5)$ & \\
\hline Rs10786712 (SNP4 & & & & & & & & & & \\
\hline Genotyping & CC & $114(23.7)$ & $96(20.8)$ & 0.407 & 64 (23.5) & $51(21.3)$ & 0.055 & $50(23.9)$ & $45(20.2)$ & 0.264 \\
\hline & $C T$ & $239(49.7)$ & $228(49.4)$ & & $142(52.2)$ & $107(44.8)$ & & $97(46.4)$ & $121(54.3)$ & \\
\hline & $\pi$ & $128(26.6)$ & $138(29.9)$ & & $66(24.3)$ & $81(33.9)$ & & $62(29.7)$ & $57(25.6)$ & \\
\hline Recessive model & $\pi$ & 128 (26.6) & 138 (29.9) & 0.266 & $66(24.3)$ & 81 (33.9) & 0.016 & $62(29.7)$ & $57(25.6)$ & 0.340 \\
\hline & $\mathrm{CC}+\mathrm{CT}$ & $353(73.4)$ & $324(70.1)$ & & $206(75.7)$ & $158(66.1)$ & & 147 (70.3) & $166(74.4)$ & \\
\hline Dominant model & CC & $114(23.7)$ & $96(20.8)$ & 0.281 & $64(23.5)$ & $51(21.3)$ & 0.554 & $50(23.9)$ & $45(20.2)$ & 0.348 \\
\hline
\end{tabular}


Table 2 Genotype and Allele distributions in patients with CAD and control participants (Continued)

\begin{tabular}{|c|c|c|c|c|c|c|c|c|c|c|}
\hline & $C T+T T$ & 367 (76.3) & $366(79.2)$ & & $208(76.5)$ & $188(78.7)$ & & 159 (76.1) & $178(79.8)$ & \\
\hline \multirow[t]{2}{*}{ Additive model } & $C T$ & $239(49.7)$ & $228(49.4)$ & 0.917 & $142(52.2)$ & 107 (44.8) & 0.093 & $97(46.4)$ & $121(54.3)$ & 0.103 \\
\hline & $C C+\pi$ & $242(50.3)$ & $234(50.6)$ & & $130(47.8)$ & $132(55.2)$ & & $112(53.6)$ & $102(45.7)$ & \\
\hline \multirow[t]{2}{*}{ Allele } & C & $467(48.5)$ & $420(45.5)$ & 0.179 & $270(49.6)$ & $209(43.7)$ & 0.059 & $197(47.1)$ & $211(47.3)$ & 0.958 \\
\hline & $\mathrm{T}$ & 495 (51.5) & $504(54.5)$ & & $274(50.4)$ & $269(56.3)$ & & $221(52.9)$ & $235(52.7)$ & \\
\hline \multicolumn{11}{|l|}{ Rs2486758 (SNP5) } \\
\hline \multirow[t]{3}{*}{ Genotyping } & CC & $14(2.9)$ & $16(3.2)$ & 0.950 & $9(3.3)$ & $10(3.8)$ & 0.912 & $5(2.4)$ & $6(2.5)$ & 0.983 \\
\hline & $C T$ & $162(33.3)$ & $164(32.8)$ & & $95(34.5)$ & 87 (33.3) & & 67 (31.6) & $77(32.2)$ & \\
\hline & $\pi$ & $311(63.9)$ & $320(64.0)$ & & $171(62.2)$ & $164(62.8)$ & & $140(66.0)$ & $156(65.3)$ & \\
\hline \multirow[t]{2}{*}{ Recessive model } & CC & $14(2.9)$ & $16(3.2)$ & 0.766 & $9(3.3)$ & $10(3.8)$ & 0.727 & $5(2.4)$ & $6(2.5)$ & 0.917 \\
\hline & $C T+T T$ & $473(97.1)$ & $484(96.8)$ & & $266(96.7)$ & $251(96.2)$ & & 207 (97.6) & $233(97.5)$ & \\
\hline \multirow[t]{2}{*}{ Dominant model } & $\pi$ & $311(63.9)$ & $320(64.0)$ & 0.964 & $171(62.2)$ & $164(62.8)$ & 0.876 & $140(66.0)$ & $156(65.3)$ & 0.864 \\
\hline & $C C+C T$ & $176(36.1)$ & $180(36.0)$ & & $104(37.8)$ & 97 (37.2) & & $72(34.0)$ & $83(34.7)$ & \\
\hline \multirow[t]{2}{*}{ Additive model } & CT & $162(33.3)$ & $164(32.8)$ & 0.877 & $95(34.5)$ & 87 (33.3) & 0.767 & 67 (31.6) & 77 (32.2) & 0.889 \\
\hline & $C C+\pi$ & $325(66.7)$ & $336(67.2)$ & & $180(65.5)$ & $174(66.7)$ & & $145(68.4)$ & $162(67.8)$ & \\
\hline \multirow[t]{2}{*}{ Allele } & C & 190 (19.5) & 196 (19.6) & 0.959 & $113(20.5)$ & 107 (20.1\% & 0.985 & 77 (18.2) & 89 (18.6) & 0.859 \\
\hline & T & $784(80.5)$ & $804(80.4)$ & & 437 (79.5) & 415 (79.5) & & 347 (81.8) & 389 (81.4) & \\
\hline
\end{tabular}

CAD, Coronary artery disease; $\mathrm{N}$, number of participants; SNP, single-nucleotide polymorphism.

maintained This is the first study to reveal the relation between CAD and CYP17A1 gene in Chinese population.

The pathogenesis of CAD includes the disorders of lipoprotein metabolism $[28,29]$, disturbance of blood coagulation and fibrinolytic system [30,31], insulin resistance or diabetes [32,33], hypertension [34,35], and the impairment and inflammation of vascular endothelium [36-38]. As previously mentioned, P450c17proteins is an important enzyme that catalyzes the formation of all endogenous androgens. Therefore, CYP17A1 genetic mutations can loss of the enzyme activity of P450c17 and potentially reduce androgen biosynthesis.

In recent years, many clinical studies showed that testosterone levels play an important role in the progress of CAD among elderly men [39], whereas lower testosterone levels promote CAD [40]. In addition, some evidences have indicated that testosterone also was related to the risk factors of CAD. For example, numerous studies have confirmed that the dysfunction of vascular endothelial as a key mechanism of occurrence and development of CAD [36-38], the levels of physiological testosterone can promote the endothelial cells release of nitric oxide (NO) through improve the vascular endothelial function, and low levels of testosterone can decrease the vascular endothelial function and promote the occurrence of CAD [41]. The disorders of lipoprotein metabolism also one of primary mechanisms of CAD [28,29], research shows there was a positive correlation between the levels of testosterone and HDL-C, and a negatively correlated between the levels of testosterone and the TG, TC, LDL-C and VLDL.

Table 3 Multiple logistic regression analysis for CAD patients and control subjects (rs1004467)

\begin{tabular}{|c|c|c|c|c|c|c|c|c|c|}
\hline & \multicolumn{3}{|l|}{ Total } & \multicolumn{3}{|l|}{ Men } & \multicolumn{3}{|c|}{ Woman } \\
\hline & OR & $95 \% \mathrm{Cl}$ & $\mathbf{P}$ & $\overline{O R}$ & $95 \% \mathrm{Cl}$ & $\mathbf{P}$ & OR & $95 \% \mathrm{Cl}$ & $\mathbf{P}$ \\
\hline Dominant model (CC + CT vs TT) & 1.024 & $0.766-1.370$ & 0.872 & 0.731 & $0.498-1.075$ & 0.112 & 1.623 & $1.023-2.576$ & 0.040 \\
\hline Hypertension & 0.988 & $0.729-1.340$ & 0.939 & 0.955 & $0.635-1.436$ & 0.825 & 1.082 & $0.670-1.748$ & 0.747 \\
\hline Diabetes & 2.485 & $1.619-3.812$ & $<0.001$ & 2.246 & $1.248-4.044$ & 0.007 & 2.957 & $1.556-5.619$ & 0.001 \\
\hline Smoking & 1.490 & $0.827-2.676$ & 0.184 & 1.381 & $0.748-2.549$ & 0.303 & 2.291 & $0.180-29.077$ & 0.523 \\
\hline Drinking, & 0.908 & $0.485-1.703$ & 0.764 & 0.941 & $0.493-1.796$ & 0.845 & 0 & 0 & 1 \\
\hline Glucose & 1.147 & $1.058-1.243$ & 0.001 & 1.107 & $0.991-1.235$ & 0.071 & 1.198 & $1.065-1.347$ & 0.003 \\
\hline triglyceride & 1.088 & $1.055-1.177$ & 0.038 & 1.060 & $0.960-1.171$ & 0.249 & 1.138 & $0.988-1.310$ & 0.072 \\
\hline Creatinine & 1.099 & $1.002-1.005$ & 0.011 & 1.009 & $1.000-1.018$ & 0.046 & 1.004 & $0.991-1.016$ & 0.567 \\
\hline SBP & 1.003 & $0.997-1.009$ & 0.271 & 1.001 & $0.993-1.009$ & 0.851 & 1.006 & $0.997-1.015$ & 0.191 \\
\hline
\end{tabular}

CAD, Coronary artery disease; $\mathrm{OR}$, odds ratios; $95 \% \mathrm{Cl}$, $95 \%$ confidence intervals; SBP, systolic blood pressure. 
Table 4 Multiple logistic regression analysis for CAD patients and control subjects (rs4919687)

\begin{tabular}{|c|c|c|c|c|c|c|c|c|c|}
\hline & \multicolumn{3}{|l|}{ Total } & \multicolumn{3}{|l|}{ Men } & \multicolumn{3}{|c|}{ Woman } \\
\hline & OR & $95 \% \mathrm{Cl}$ & $\mathbf{P}$ & OR & $95 \% \mathrm{Cl}$ & $\mathbf{P}$ & OR & $95 \% \mathrm{Cl}$ & $\mathbf{P}$ \\
\hline Recessive model (AG + GG vs AA) & 0.673 & $0.372-1.217$ & 0.190 & 1.324 & $0.512-3.428$ & 0.563 & 0.417 & $0.188-0.926$ & 0.032 \\
\hline Hypertension & 1.001 & $0.738-1.358$ & 0.996 & 0.958 & $0.637-1.442$ & 0.838 & 1.155 & $0.717-1.862$ & 0.55 \\
\hline Diabetes & 2.484 & $1.618-3.814$ & $<0.001$ & 2.370 & $1.310-4.289$ & 0.004 & 2.857 & $1.508-5.411$ & 0.001 \\
\hline Smoking & 1.546 & $0.853-2.803$ & 0.151 & 1.455 & $0.783-2.701$ & 0.235 & 2.959 & $2.33-37.579$ & 0.403 \\
\hline Drinking, & 0.861 & $0.455-1.629$ & 0.645 & 0.864 & $0.449-1.662$ & 0.662 & 0 & 0 & 1 \\
\hline Glucose & 1.154 & $1.063-1.253$ & 0.001 & 1.094 & $0.979-1.223$ & 0.114 & 1.218 & $1.080-1.373$ & 0.001 \\
\hline triglyceride & 1.096 & $1.012-1.187$ & 0.024 & 1.064 & $0.963-1.175$ & 0.224 & 1.154 & $1.003-1.327$ & 0.045 \\
\hline Creatinine & 1.009 & $1.002-1.015$ & 0.013 & 1.009 & $1.000-1.018$ & 0.054 & 1.003 & $0.991-1.016$ & 0.606 \\
\hline SBP & 1.003 & $0.997-1.009$ & 0.272 & 1.001 & $0.993-1.009$ & 0.853 & 1.005 & $0.996-1.014$ & 0.246 \\
\hline
\end{tabular}

CAD, Coronary artery disease; OR, odds ratios; $95 \% \mathrm{Cl}, 95 \%$ confidence intervals; SBP, systolic blood pressure.

Malkin et al. also confirmed that the low levels of testosterone can lead to lipid disorders, and supplement testosterone can correct dyslipidemia [42]. Insulin resistance and diabetes are the significant independent risk factors for CAD $[32,33]$. Selvin et al. indicated that there is a relationship between diabetes and the low free or low bioactive testosterone levels [43]. Blood coagulation and fibrinolytic system is the important mechanism of the CAD [30,31], physiological levels of testosterone can improve the function of endothelial cells [44], low levels of testosterone can increase the proteins related to clotting factor VIII, causing endothelial dysfunction and vascular inflammatory reaction, finally, platelet adhesion in the damaged blood vessels, resulting in the incidence of CAD. Androgens serve as precursors to estrogens, so normal estrogen signaling is also dependent on CYP17A1. Estrogen plays a very important role in many other physiological and pathological process, such as mediation vasoconstriction, vascular endothelium repair and lipid metabolism, involves in glucose metabolism and insulin related signal transduction pathways, etc., which are directly or indirectly affect the function of cardiovascular system. Wellons et al. reported that early menopause is associated with an increased risk of CAD [45], as well as high levels of endogenous estrogen explain the low prevalence of CAD in premenopausal women [46]. It is worth noting that the protective value of sex hormones appears to be sex-specific, high levels of estrogen and oestrone in men are associated with an increased risk of and CAD [39].

In our study, we found that polymorphisms of CYP17A1 were associated with risk of CAD in a Han population. For rs10786712, in men, the recessive model $(C C+C T$ vs TT) was significantly higher in control subjects than in CAD patients, after multivariate adjustment of confounding factors such as plasma concentration of TG, Glu, Cr, incidence of hypertension, diabetes, drinking, and smoking for CAD, the significant difference was retained. This indicated that the TT genotype might be protecting against for CAD in men. For rs1004467 and rs4919687, in women, the dominant model (rs1004467) and recessive model (rs4919687) were significantly higher in CAD subjects than in control participants, after multivariate adjustment of confounding factors, the significant difference was retained. This result indicated that $\mathrm{CC}$ genotype of

Table 5 Multiple logistic regression analysis for CAD patients and control subjects (rs10786712)

\begin{tabular}{|c|c|c|c|c|c|c|c|c|c|}
\hline & \multicolumn{3}{|l|}{ Total } & \multicolumn{3}{|l|}{ Men } & \multicolumn{3}{|c|}{ Woman } \\
\hline & OR & $95 \% \mathrm{Cl}$ & $\mathbf{P}$ & OR & $95 \% \mathrm{Cl}$ & $\mathbf{P}$ & OR & $95 \% \mathrm{Cl}$ & $\mathbf{P}$ \\
\hline Recessive model $(C C+C T$ vs TT) & 1.193 & $0.879-1.619$ & 0.259 & 1.644 & $1.087-2.488$ & 0.019 & 0.786 & $0.495-1.248$ & 0.308 \\
\hline Hypertension & 1.010 & $0.742-1.377$ & 0.947 & 0.996 & $0.655-1.513$ & 0.985 & 1.117 & $0.691-1.805$ & 0.651 \\
\hline Diabetes & 2.305 & $1.481-3.587$ & $<0.001$ & 2.458 & $1.313-4.600$ & 0.005 & 2.433 & $1.278-4.630$ & 0.007 \\
\hline Smoking & 1.523 & $0.833-2.785$ & 0.172 & 1.421 & $0.756-2.669$ & 0.275 & 2.637 & $0.210-33.171$ & 0.453 \\
\hline Drinking, & 0.825 & $0.434-1.567$ & 0.556 & 0.835 & $0.431-1.618$ & 0.593 & 0 & 0 & 1 \\
\hline Glucose & 1.171 & $1.075-1.276$ & $<0.001$ & 1.111 & $0.988-1.250$ & 0.079 & 1.227 & 1.084- 1.388 & 0.001 \\
\hline triglyceride & 1.082 & $0.999-1.571$ & 0.052 & 1.062 & $0.960-1.175$ & 0.243 & 1.134 & $0.986-1.304$ & 0.077 \\
\hline Creatinine & 1.009 & $1.001-1.016$ & 0.010 & 1.010 & $1.000-1.019$ & 0.046 & 1.005 & 0.993- 1.017 & 0.433 \\
\hline SBP & 1.002 & $0.996-1.008$ & 0.492 & 0.999 & $0.990-1.007$ & 0.795 & 1.005 & $0.996-1.014$ & 0.281 \\
\hline
\end{tabular}

CAD, Coronary artery disease; $\mathrm{OR}$, odds ratios; $95 \% \mathrm{Cl}$, $95 \%$ confidence intervals; SBP, systolic blood pressure. 
Table 6 Pairwise linkage disequilibrium for five SNPs

\begin{tabular}{lllllll}
\hline$\left|D^{\prime}\right|$ values & & & & & & \\
\hline$r^{2}$ values & & SNP1 & SNP2 & SNP3 & SNP4 & SNP5 \\
& SNP1 & & 0.575 & 0.911 & 1.000 & 0.913 \\
& SNP2 & 0.035 & & 0.470 & 0.567 & 0.630 \\
& SNP3 & 0.407 & 0.049 & & 0.874 & 0.723 \\
& SNP4 & 0.123 & 0.219 & 0.194 & & 0.926 \\
SNP5 & 0.028 & 0.074 & 0.036 & 0.236 & \\
\hline
\end{tabular}

$\left|\mathrm{D}^{\prime}\right|$ above the diagonal and $\mathrm{r}^{2}$ below the diagonal. rs1004467 and AA genotype of rs4919687 are risk factor for CAD in women.

In addition, we hypothesized that haplotype analysis would be useful for the assessment of association between haplotypes and CAD. For men, we found a susceptible haplotype [A-C-T (SNP1-SNP4-SNP5)], and a protective haplotype [A-T-T (SNP1-SNP4-SNP5)]. And these haplotypic analysis results were consistent with the genotypic analysis results of SNP4 (rs10786712) that the CC genotype confers risk and the TT genotype is protective. For women, significant differences were found for the frequency of occurrence of the haplotype (A-T of SNP3-SNP5, A-A-T of SNP1-SNP3-SNP4, A-A-T of

Table 7 Haplotype analysis in patients with CAD and in control subjects

\begin{tabular}{|c|c|c|c|c|c|c|c|c|c|c|c|c|c|c|c|c|}
\hline \multirow[t]{2}{*}{ Haplotype } & \multirow[t]{2}{*}{ No. 1} & \multirow[t]{2}{*}{ No. 2} & \multirow[t]{2}{*}{ No. 3} & \multirow[t]{2}{*}{ No. 4} & \multicolumn{3}{|c|}{ Overall $P$ value } & \multicolumn{3}{|c|}{ Frequency in total } & \multicolumn{3}{|c|}{ Frequency in man } & \multicolumn{3}{|c|}{ Frequency in woman } \\
\hline & & & & & Total & Man & Woman & CAD & Control & $P$ value & CAD & Control & $P$ value & CAD & Control & $P$ value \\
\hline & & SNP3 & & SNP5 & 0.877 & 0.340 & 0.105 & & & & & & & & & \\
\hline $\mathrm{H} 1$ & & A & & $\mathrm{T}$ & & & & 0.217 & 0.206 & 0.617 & 0.188 & 0.222 & 0.190 & 0.249 & 0.189 & 0.041 \\
\hline $\mathrm{H} 2$ & & G & & C & & & & 0.183 & 0.182 & 0.985 & 0.188 & 0.196 & 0.754 & 0.170 & 0.167 & 0.951 \\
\hline \multirow[t]{2}{*}{ H3 } & & G & & $\mathrm{T}$ & & & & 0.591 & 0.597 & 0.686 & 0.609 & 0.570 & 0.182 & 0.573 & 0.627 & 0.074 \\
\hline & & & SNP4 & SNP5 & 0.399 & 0.099 & 0.964 & & & & & & & & & \\
\hline $\mathrm{H} 1$ & & & C & C & & & & 0.192 & 0.186 & 0.793 & 0.201 & 0.195 & 0.857 & 0.180 & 0.177 & 0.985 \\
\hline $\mathrm{H} 2$ & & & C & $\mathrm{T}$ & & & & 0.294 & 0.268 & 0.235 & 0.299 & 0.241 & 0.047 & 0.288 & 0.296 & 0.787 \\
\hline \multirow[t]{2}{*}{ H3 } & & & $\mathrm{T}$ & $\mathrm{T}$ & & & & 0.509 & 0.535 & 0.201 & 0.494 & 0.550 & 0.055 & 0.528 & 0.520 & 0.854 \\
\hline & SNP1 & SNP3 & SNP4 & & 0.612 & 0.167 & 0.155 & & & & & & & & & \\
\hline $\mathrm{H} 1$ & A & A & $\mathrm{T}$ & & & & & 0.094 & 0.094 & 0.981 & 0.070 & 0.104 & 0.053 & 0.127 & 0.082 & 0.034 \\
\hline $\mathrm{H} 2$ & $A$ & G & $C$ & & & & & 0.471 & 0.446 & 0.280 & 0.487 & 0.436 & 0.102 & 0.449 & 0.456 & 0.834 \\
\hline \multirow[t]{2}{*}{$\mathrm{H} 3$} & A & G & T & & & & & 0.299 & 0.327 & 0.192 & 0.307 & 0.324 & 0.552 & 0.290 & 0.331 & 0.189 \\
\hline & SNP1 & SNP3 & & SNP5 & 0.961 & 0.225 & 0.154 & & & & & & & & & \\
\hline $\mathrm{H} 1$ & A & A & & $\mathrm{T}$ & & & & 0.098 & 0.096 & 0.933 & 0.067 & 0.103 & 0.040 & 0.135 & 0.088 & 0.035 \\
\hline $\mathrm{H} 2$ & A & G & & $C$ & & & & 0.186 & 0.181 & 0.795 & 0.192 & 0.194 & 0.972 & 0.173 & 0.167 & 0.853 \\
\hline \multirow[t]{2}{*}{$\mathrm{H} 3$} & C & A & & $\mathrm{T}$ & & & & 0.116 & 0.109 & 0.701 & 0.119 & 0.117 & 0.893 & 0.110 & 0.102 & 0.742 \\
\hline & SNP1 & & SNP4 & SNP5 & 0.415 & 0.117 & 0.986 & & & & & & & & & \\
\hline $\mathrm{H} 1$ & A & & $C$ & T & & & & 0.295 & 0.268 & 0.225 & 0.302 & 0.242 & 0.040 & 0.286 & 0.296 & 0.733 \\
\hline $\mathrm{H} 2$ & A & & T & $\mathrm{T}$ & & & & 0.385 & 0.419 & 0.104 & 0.364 & 0.427 & 0.031 & 0.415 & 0.411 & 0.953 \\
\hline \multirow[t]{2}{*}{$\mathrm{H} 3$} & C & & T & $\mathrm{T}$ & & & & 0.122 & 0.115 & 0.668 & 0.127 & 0.121 & 0.830 & 0.114 & 0.109 & 0.830 \\
\hline & & SNP3 & SNP4 & SNP5 & 0.463 & 0.211 & 0.282 & & & & & & & & & \\
\hline $\mathrm{H} 1$ & & $A$ & $\mathrm{~T}$ & $\mathrm{~T}$ & & & & 0.211 & 0.205 & 0.776 & 0.190 & 0.221 & 0.219 & 0.239 & 0.187 & 0.071 \\
\hline $\mathrm{H} 2$ & & G & C & C & & & & 0.180 & 0.177 & 0.905 & 0.190 & 0.189 & 0.968 & 0.165 & 0.164 & 0.976 \\
\hline \multirow[t]{2}{*}{$\mathrm{H} 3$} & & G & C & $T$ & & & & 0.291 & 0.266 & 0.239 & 0.297 & 0.241 & 0.048 & 0.284 & 0.292 & 0.761 \\
\hline & SNP1 & SNP3 & SNP4 & SNP5 & 0.577 & 0.098 & 0.302 & & & & & & & & & \\
\hline $\mathrm{H} 1$ & A & A & $\mathrm{T}$ & T & & & & 0.092 & 0.094 & 0.878 & 0.066 & 0.103 & 0.033 & 0.127 & 0.084 & 0.045 \\
\hline $\mathrm{H} 2$ & A & G & $C$ & $C$ & & & & 0.181 & 0.177 & 0.851 & 0.191 & 0.189 & 0.949 & 0.169 & 0.165 & 0.913 \\
\hline H3 & A & G & C & $\mathrm{T}$ & & & & 0.292 & 0.226 & 0.221 & 0.300 & 0.243 & 0.039 & 0.280 & 0.290 & 0.693 \\
\hline $\mathrm{H} 4$ & A & G & $\mathrm{T}$ & $\mathrm{T}$ & & & & 0.294 & 0.326 & 0.124 & 0.297 & 0.324 & 0.360 & 0.291 & 0.329 & 0.213 \\
\hline $\mathrm{H} 5$ & C & $A$ & T & $\mathrm{T}$ & & & & 0.117 & 0.110 & 0.673 & 0.121 & 0.116 & 0.817 & 0.110 & 0.103 & 0.753 \\
\hline
\end{tabular}


SNP1-SNP3-SNP5, and A-A-T-T of SNP1-SNP3-SNP4SNP5, respectively).

There are still several limitations must be mentioned in the present study. Firstly, we did not perform enzymatic LDL, which would decrease the mean and SD of the LDL results. Secondly, we did not collect the data on lipid-lowering drug levels and drug compliance. Finally, this study was limited by the relatively small sample size, it needs a large number of clinical samples and investigation of other SNPs of CYP17A1 in future studies.

\section{Conclusion}

In conclusion, this is the first study to investigate the differences between the human CYP17A1 and CAD in Han population of China, and is the first haplotype-based case-control study and to correlations its association with CAD. Rs1004467, rs4919687, rs10786712 of CYP17A1gene are associated with CAD in Han population of China. The TT genotype of rs10786712 could be a protective genetic marker of CAD in men. The CC genotype of rs1004467 and the AA genotype of rs4919687 could be two risk genetic marker of CAD in women. However, large sample size study including other SNPs of CYP17A1 should be performed in future studies.

\section{Competing interests}

The authors declared that they have no competing interests.

\section{Authors' contributions}

$X X$ and CFD conceived the study, participated in the design, collected the data, performed statistical analyses, performed the genotyping, and drafted the manuscript. ZYF, YYZ, YTM, YNY and XML conceived the study and revised manuscript. FL, BDC and MTG participated in the design, and helped to draft the manuscript. All authors read and approved the final manuscript.

\section{Acknowledgements}

This study was supported by National Natural Science Foundation of China (81160017 and 81470014) and Xinjiang Science and Technology Projects (201491181).

Received: 4 October 2014 Accepted: 29 January 2015

Published online: 07 March 2015

References

1. Manace LC, Godiwala TN, Babyatsky MW. Genomics of cardiovascular disease. Mt Sinai J Med. 2009;76:613-23.

2. Zee RY1, Cheng S, Hegener HH, Erlich HA, Ridker PM. Genetic variants of arachidonate 5-lipoxygenase-acti-vating protein, and risk of incident myocardial infarction and ischemic stroke: a nested case-control approach. Stroke. 2006:37:2007-11.

3. Maouche S, Schunkert H. Strategies beyond genome-wide association studies for atherosclerosis. Arterioscler Thromb Vasc. 2012;32:170-81.

4. Roberts R, Stewart AF. Genes and coronary artery disease: where are we? J Am Coll Cardiol. 2012;60:1715-21.

5. Nordlie MA, Wold LE, Kloner RA. Genetic contributors toward increased risk for 301 ischemic heart disease. J Mol Cell Cardiol. 2005;39:667-79.

6. Damani SB, Topol EJ. Emerging genomic applications in coronary artery disease. J ACC Cardiovasc. 2011:4:473-82.

7. O'Donnell CJ, Kavousi M, Smith AV, Kardia SL, Feitosa MF, Hwang SJ. Genome-wide association study for coronary artery calcification with follow-Up in myocardial infarction. J Circulation. 2012:124:2855-64.

8. Schunkert H, König IR, Kathiresan S, Reilly MP, Assimes TL, Holm H. Large-scale association analysis identifies 13 new susceptibility loci for coronary artery disease. J Nat Genet. 2011:43:333-8.
9. Zordoky BN, El-Kadi AO. Effect of cytochrome P450 polymorphism on arachidonic acid metabolism and their impact on cardiovascular diseases. Pharmacol Ther. 2010;125:446-63.

10. Elbekai RH, El-Kadi AO. Cytochrome P450 enzymes: central players in cardiovascular health and disease. Pharmacol Ther. 2006;112:564-87.

11. Nakayama T, Soma M, Rehemudula D, Takahashi Y, Tobe H, Satoh M. Association of $5^{\prime}$ upstream promoter region of prostacyclin synthase gene variant with cerebral infarction. Am J Hypertens. 2000;13:1263-7.

12. Wang XL, Greco M, Sim AS, Duarte N, Wang J, Wilcken DE. Effect of CYP1A1 Mspl polymorphism on cigarette smoking related coronary artery disease and diabetes. Atherosclerosis. 2002;162:391-7.

13. Cornelis MC, El-Sohemy A, Campos H. Genetic polymorphism of CYP1A2 increases the risk of myocardial infarction. J Med Genet. 2004;41:758-62.

14. Yasar U1, Bennet AM, Eliasson E, Lundgren S, Wiman B, De Faire U, et al. Allelic variants of cytochromes P450 2C modify the risk for acute myocardial infarction. Pharmacogenetics. 2003;13:715-20.

15. Spiecker M, Darius $H$, Hankeln T, Soufi M, Sattler AM, Schaefer JR, et al. Risk of coronary artery disease associated with polymorphism of the cytochrome P450 epoxygenase CYP2J2. Circulation. 2004;110:2132-6.

16. Hengstenberg C1, Holmer SR, Mayer B, Löwel H, Engel S, Hense HW, et al. Evaluation of the aldosterone synthase (CYP11B2) gene polymorphism in patients with myocardial infarction. Hypertension. 2000;35:704-9.

17. Letonja M, Peterlin B, Bregar D, Petrovic D. Are the T/C polymorphism of the CYP17 gene and the tetranucleotide repeat (TTA) polymorphism of the CYP19 gene genetic markers for premature coronary artery disease in Caucasians? Folia Biol (Praha). 2005;51:76-81.

18. Fan YM1, Raitakari OT, Kähönen M, Hutri-Kähönen N, Juonala M, Marniemi J, et al. Hepatic lipase promoter C-480 T polymorphism is associated with serum lipids levels, but not subclinical atherosclerosis: the Cardiovascular Risk in Young Finns Study. Clin Genet. 2009;76:46-53.

19. Nehal N, Mehta MD. MSCE: Large-Scale Association Analysis Identifies 13 New Susceptibility Loci for Coronary Artery Disease. Circ Cardiovasc Genet. 2011:4:327-9.

20. Schunkert H1, König IR, Kathiresan S, Reilly MP, Assimes TL, Holm H, et al. Large-scale association analyses identifies 13 new susceptibility loci for coronary artery disease. Nat Genet. 2011;43:333-8.

21. Butterworth AS, Braund PS, Farrall M. Large-scale gene-centric analysis identifies novel variants for coronary artery disease. PLoS Genet. 2011;7:e1002260.

22. American Diabetes Association. Clinical practice recommendations. Diabetes Care. 1997;20:S1-S70.

23. Nakayama T, Soma M, Rahmutula D, Ozawa Y, Kanmatsuse K. Isolation of the 5 -flanking region of genes by thermal asymmetric interlaced polymerase chain reaction. Med Sci Monit. 2001;7:345-9.

24. Xiang $X, M a ~ Y T, F u Z Y$, Yang YN, Xiang M, Chen BD, et al. Haplotype Analysis of the CYP8A1 gene associated with myocardial infarction. Clin Appl Thromb-Hem. 2009;15:574-80

25. Xie X, Ma YT, Fu ZY, Yang YN, Ma X, Chen BD, et al. Association of polymorphisms of PTGS2 and CYP8A1 with myocardial infarction. Clin Chem Lab Med. 2009;47:347-52.

26. Yang YN, Wang XL, Ma YT, Xie X, Fu ZY, Li XM, et al. Association of interaction between smoking and CYP 2C19*3 polymorphism with coronary artery disease in a Uighur population. Clin Appl Thromb Hemost. 2010;16:579-83.

27. Dempster AP, Laird NM, Rubin DB. Maximum likelihood from in complete data via the EM algorithm. J R Stat Soc. 1977;39:1-22.

28. Arsenault BJ, Lemieux I, Després JP, Wareham NJ, Kastelein JJ, Khaw KT, et al. The hypertriglyceridemic-waist phenotype and the risk of coronary artery disease: results from the EPIC-Norfolk prospective population study. CMAJ. 2010;182:1427-32.

29. Goswami B1, Rajappa M, Singh B, Ray PC, Kumar S, Mallika V. Inflammation and dyslipidaemia: a possible interplay between established risk factors in North Indian males with coronary artery disease. Cardiovasc J Afr. 2010;21:103-8

30. Maruyama I. Coagulation/fibrinolytic system and platelet in acute coronary syndrome. Nihon Rinsho. 1998:56:2488-92.

31. Folsom AR1, Aleksic N, Park E, Salomaa V, Juneja H, Wu KK. Prospective study of fibrinolytic factors and incident coronary heart disease: the Atherosclerosis Risk in Communities (ARIC) Study. Arterioscler Thromb VasC Biol. 2001;21:611-7.

32. Raz I. Relationship between blood glucose control and improved cardiovascular outcome after stent implantation in diabetic patients. Cardiology. 2010;116:48-50 
33. Reaven GM. Insulin resistance, the insulin resistance syndrome, and cardiovascular disease. Panmineva Med. 2005;47:201-10.

34. Srikanthan VS, Dunn FG. Hypertension and coronary artery disease. Med Clin North Am. 1997:81:1147-63.

35. Nakamura Y, Saitoh S, Takagi S, Ohnishi H, Chiba Y, Kato N, et al. Impact of abnormal glucose tolerance, hypertension and other risk factors on coronary artery disease. Circ J. 2007;71:20-5.

36. Mehta JL, Saldeen TG, Rand K. Interactive role of infection, inflammation and traditional risk factors in atherosclerosis and coronary artery disease. J Am Coll Cardiol. 1998;31:1217-25.

37. Farmer JA, Torre-Amione G. Atherosclerosis and inflammation. Curr Atheroscler Rep. 2002;4:92-8.

38. Kitta Y, Obata JE, Nakamura T, Hirano M, Kodama Y, Fujioka D, et al. Persistent impairment of endothelial vasomotor function has a negative impact on outcome in patients with coronary artery disease. J Am Coll Cardiol. 2009;53:323-30.

39. Naessen T1, Sjogren U, Bergquist J, Larsson M, Lind L, Kushnir MM. Endogenous steroids measured by high-specificity liquid chromatographytandem mass spectrometry and prevalent cardiovascular disease in 70-year-old men and women. J Clin Endocrinol Metab. 2010;95:1889-97.

40. Malkin CJ, Pugh PJ, Morris PD, Asif S, Jones TH, Channer KS. Low serum testosterone and increased mortality in men with coronary heart disease. Heart. 2010;96:1821-5.

41. Maturana MA1, Breda V, Lhullier F, Spritzer PM. Relationship between endogenous testosterone and cardiovascular risk in early postmenopausal women. Metabolism. 2008:57:961-5.

42. Malkin CJ1, Pugh PJ, Jones RD, Kapoor D, Channer KS, Jones TH. The effect of testosterone replacement on endogenous inflammatory eytokines and lipid profiles in hypogonadal men. J Clin Endocrinol Metab. 2004;89:3313-8.

43. Selvin $E$, Feinleib $M$, Zhang $L$. Androgens and diabetes in men results from the Third National Health and Nutrition Examination Survey (NHANES III). Diabetes Care. 2007;30:234-8.

44. Jin H, Lin J, Fu L. Physiological testosterone stimulates tissue plasminogen activator and tissue factor pathway inhibitor and inhibits plasminogen activator inhibitor type I release in endothelial cells. Biochem Cell Bid. 2007:85:246-51.

45. Wellons M, Ouyang P, Schreiner PJ. Early menopause predicts future coronary heart disease and stroke: the Multi-Ethnic Study of Atherosclerosis. Menopause. 2012:19:1081-7.

46. Mendelsohn ME, Karas RH. The protective effects of estrogen on the cardiovascular system. N Engl J Med. 1999;340:1801-11.

\section{Submit your next manuscript to BioMed Central and take full advantage of:}

- Convenient online submission

- Thorough peer review

- No space constraints or color figure charges

- Immediate publication on acceptance

- Inclusion in PubMed, CAS, Scopus and Google Scholar

- Research which is freely available for redistribution 